\title{
Letter to the Editor: Undergraduate Surgical Training During COVID 19 Pandemic - the Lessons Learned
}

\author{
Mithilesh Kumar Sinha ${ }^{1}$ Apurba Barman ${ }^{2}$
}

Accepted: 5 July 2021 / Published online: 10 July 2021

(C) Société Internationale de Chirurgie 2021

Medical schools were closed during the COVID 19 pandemic, and there was a realization that the situation will not improve for a long time. We needed young clinicians, but the undergraduate medical education was compromised. Very soon, we shifted the basic science classes to online platforms, but the clinical and surgical skills training needed innovations. There was a need to conduct at least a part of clinical training on the virtual platform. Calhoun KE et al. proposed two weeks of virtual clerkship in the third year of undergraduate teaching (MS3s) and recommended the "required patient care encounter topics" and the "Secondary topics" for this [1]. The actual execution of such a plan was done by Namani Silva ON et al., who introduced EMLR (surgically focused extended mastery learning rotation) at the University of California, San Francisco. Video conferencing sessions were organized where the senior medical students, surgical residents and attendings actively participated and encouraged the MS3s to prepare diagnostic schemas and illness scripts. A layered learning environment was created to practice the art of reaching the diagnosis. These sessions prepared the students for clinical encounters [2].

The students needed training on communication skills for different clinical scenarios. Newcomb AB et al. from George Washington school of medicine experimented on this aspect of training. They used teleconferencing and

Mithilesh Kumar Sinha

mks132@gmail.com

Apurba Barman

apurvaa23@gmail.com

1 Department of General Surgery, AIIMS Bhubaneswar, Room no-401, Academic block, Bhubaneswar, Odisha 751019, India

2 Department of Physical Medicine and Rehabilitation, AIIMS Bhubaneswar, Bhubaneswar, Odisha 751019, India role-play to teach fourth-year students communication skills with patients and their attendants. The students found these sessions very interactive and insightful [3].

Skills training is an essential aspect of surgical education, and Schlégl ÁT et al. attempted this through a distance education program. They used readily available tools like shoelaces and threads, bent sewing needles, precision plyers and eyebrow tweezers for suturing and knotting. They prepared pelvitrainers with cardboard and smartphone for learning laparoscopic maneuvres. All the training and practice sessions were conducted online. At the end of the session, an online examination was conducted. The results were comparable to traditional skills training [4].

This pandemic has given us new ways of thinking and an opportunity to challenge traditional teaching techniques. We learned the importance of planning and making goals at the time of crisis. We divided the challenges of training into multiple subgroups and then approached each aspect with innovation. We learned to use virtual platforms as a bridge to social distancing. With the receding tide of the pandemic, we are probably entering a new era of surgical teaching.

Funding We have not received any funding for this project.

Declarations

Conflict of interest None.

Human and Animal Rights All procedures followed were in accordance with the ethical standards of the responsible committee on human experimentation (institutional and national) and with the Helsinki Declaration of 1975, as revised in 2008 (5). The study was approved by the institutional ethics committee of AIIMS Bhubaneswar.

Informed Consent Informed written consent was obtained from all patients for being included in the study. 


\section{References}

1. Calhoun KE, Yale LA, Whipple ME, Allen SM, Wood DE, Tatum RP (2020) The impact of COVID-19 on medical student surgical education: Implementing extreme pandemic response measures in a widely distributed surgical clerkship experience. Am J Surg 220(1):44-47

2. Nnamani Silva ON, Hernandez S, Kim EH, Kim AS, Gosnell J, Roman SA et al (2021) Surgery clerkship curriculum changes at an academic institution during the COVID-19 pandemic. J Surg Educ 78(1):327-331

3. Newcomb AB, Duval M, Bachman SL, Mohess D, Dort J, Kapadia MR (2021) Building rapport and earning the surgical patient's trust in the era of social distancing: teaching patient-centered communication during video conference encounters to medical students. J Surg Educ 78(1):336-341

4. Schlégl ÁT, Pintér Z, Kovács A, Kopjár E, Varga P, Kardos D, et al. (2020) Teaching Basic Surgical Skills Using Homemade Tools in Response to COVID-19. Acad Med [Internet]. 2020 July 14 [cited 2021 June 3]; Available from: https://www.ncbi.nlm.nih. gov/pmc/articles/PMC7363365/

Publisher's Note Springer Nature remains neutral with regard to jurisdictional claims in published maps and institutional affiliations. 